\title{
Structural response of collision between bow and ice
}

\section{row}

\author{
Lin Wang, Lei Huang, Xiang Jiang
}

\begin{abstract}
With the development of modern industrialization, the impact of human activities on the global environment and climate is increasingly intensified. Existing meteorological record data show that global temperature is rising, many years has started to melt the ice, arctic and Antarctic waters poles vast land and storage of the rich resources has become the focus of attention all over the world, human polar trip is not only limited to the research, development of polar are gradually fading, which greatly increased the demand for polar shipping. Polar transport ships core research represents a national key problem of ship construction level, and restricts the notion of a country, affecting the new pattern of the world, in the high latitudes of port and waterway will usher in an unprecedented boom, however, because of the high latitudes still exists a lot of ice, the world is brought by the ice load is unable to avoid related issues, if ship collided with the floating ice, in the event of structural damage or oil and gas leakage accident, the consequences are often the immeasurable
\end{abstract}

Index Terms - Ship-ice collision Stem structure Collision force Damage deformation Energy absorption.

\section{INTRODUCTION}

An ice raft is a large piece of floating ice . Every severe winter, large ice floes appear in rivers in northern China. Of course, this phenomenon is not only in the rivers, the arctic and Antarctic ice floes are always present. Once thawed, these ice floes will float with currents and ocean currents in any river, sea or lake There are always ice floes floating in popular shipping lanes, and the presence of these ice floes greatly increases the danger to ships in the shipping lanes. In this section, ice floes are defined as large sheets of laminar ice for ease of exploration. Under normal circumstances, the sea ice encountered by ships sailing has two forms, which are mass ice and large area ice respectively. Ships sailing in the ice region, especially in the polar region, sometimes collision with ice rows becomes inevitable[1]. Therefore, it is quite necessary to study ship structure and ice row collision damage.

Based on the existing ship finite element model, a new ice platoon finite element model is built in this paper. According to the characteristics of ice platoon, it is easy to see that the thickness, velocity and properties of ice platoon all affect the structural response of the collision to different degrees. In this paper, ls-dyna is used to simulate the collision between ships and ice platoon, Under certain other conditions[2], starting from the three aspects of ice row thickness, motion state and single impact parameter change of physical properties, The differences in damage deformation, collision force and velocity variation of ships under different collision conditions

Lin Wang, Lei Huang, Xiang Jiang, School of Naval Architecture \& Ocean Engineering, Jiangsu University of Science and Technology, Zhenjiang, Jiangsu ,China are compared and studied, The influence of the above factors on the collision between the two is summarized, which provides a reference for improving the crashworthiness of ships and the design of anti-ice loading capacity.

\section{CRASH SCENE}

\section{A. Finite element simulation model of ice platoon}

In high latitude areas, there are a large number of ice sheets drifting under the action of wind and water, as shown in FIG. 1.1. Moreover, due to a variety of complex factors, the shape of the ice often strange. Among them, the ice is thick and thin, some cover the water completely, while others scatter on the water like lotus leaves. Collisions are inevitable when ships are sailing on ice. However, in the strange shape of an ice raft, all circumstances should be taken into account. Therefore, the ice row model mesh, size[3], thickness and other factors should be determined with special care. Figure 1.1 shows several ice cubes with different shapes.

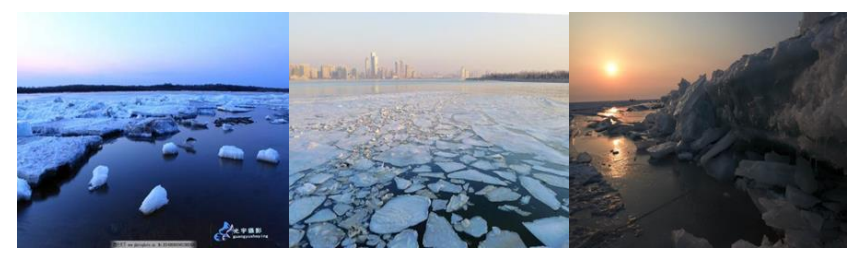

Fig. 1.1 Different shapes of ice platoon

Because in the ship-to-ice row collision, the bow only needs to expand the channel along the bow, Therefore, only using the bow finite element model to simulate collision between ship and ice row can greatly shorten the calculation time and save unnecessary memory space. In this paper, the width of ice row is $80 \mathrm{~m}$ and the width of bow is $40 \mathrm{~m}$. Through literature review and verification of simulation results, it is proved that both widths are reasonable. Collision time was set at 2.0 seconds and bow collision velocity was $5 \mathrm{~m} / \mathrm{s}$. To make computing easier and more efficient. The grid of ice rows is divided into three zones -- collision zone, transition zone and distal zone. The mesh density decreases successively, and the mesh size of the collision zone is $0.5 \mathrm{~m}$. Ice row grid division is shown in figure 1.2.

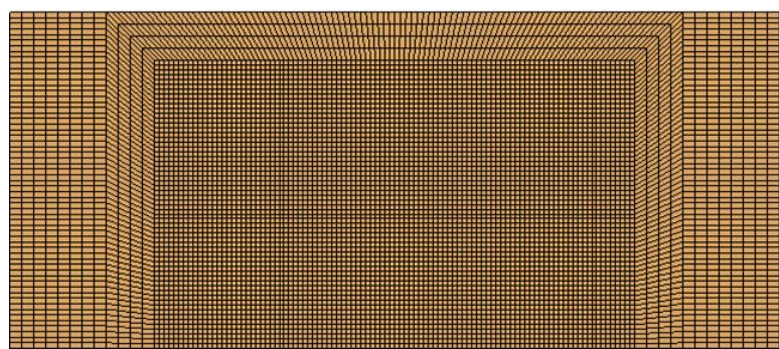

Fig. 1.2 Finite element model of ice platoon 


\section{B. Collision solution}

The finite element model of bow of ice collision is the simplified bow model of 16kDWT shuttle tanker. Ls-dyna was used to simulate the collision of the established ship ice model. The collision location was the center of the ice row, and the center lines of the two were consistent. The collision speed of the bow was $5 \mathrm{~m} / \mathrm{s}$, and the finite element model of the collision was shown in figure 1.3.

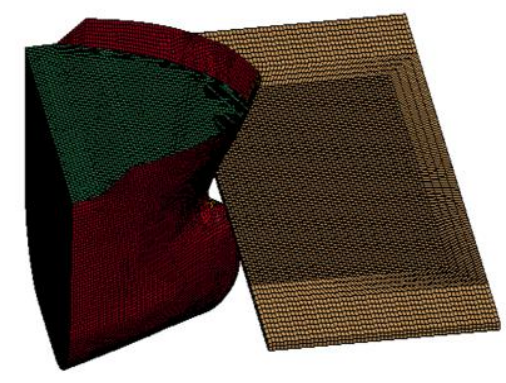

Fig. 1.3 Finite element model of collision between bow and ice row

The formation of ice row is influenced by temperature, salt in water, water environment and other factors, so the ice row changes in a variety of ways. In this paper, considering the ice thickness, motion state and physical properties, three groups of schemes are designed to explore the analysis and research on the structural damage of bow under ice load:

Scheme I: Three working conditions were designed in terms of ice thickness. The thicknesses of working conditions $\mathrm{A}, \mathrm{B}$ and $\mathrm{C}$ were set as $0.8 \mathrm{~m}, 1 \mathrm{~m}$ and $1.2 \mathrm{~m}$ respectively. The physical properties of the ice discharge movement in the three conditions are the same. All four sides of an ice racquet are fixed except for the direction of collision.

Scheme II: Starting from the motion state of ice platoon, three working conditions are designed. The thickness of the ice is $1 \mathrm{~m}$, and the motion state of the working condition $\mathrm{A}$ is the same as that in scheme one. Working condition B is free and unrestrained and moves in the opposite direction along the ship at the speed of $3 \mathrm{~m} / \mathrm{s}$. In condition C, the ice platoon is free floating with no initial velocity[4]. The physical properties of the ice under all three conditions are the same.

Scheme III: Starting from the physical properties of ice platoon, three working conditions were designed. The physical properties of the ice platoon in condition A are the same as those in scheme I and II. Working condition B appropriately increases the shear modulus of the ice bank, and other physical properties remain unchanged. Working condition $\mathrm{C}$ appropriately increases the yield strength of the ice platoon, while other physical properties remain unchanged The thickness of the ice in the three working conditions was $0.8 \mathrm{~m}$, and the motion state was the same as that in plan I.

In the course of collision, the ship is in longitudinal motion, namely longitudinal advance and retreat motion. Attached water mass of longitudinal retreat and retreat motion is generally determined by empirical formula:

$$
X_{H}=(t)=-m_{x x} u
$$

Due to the fact that the attached water mass MXX ii is very small compared with the hull mass $m$ during the longitudinal movement of ships, the attached water mass can be directly applied to the hull model mass. Motora (1960) found that the attached water mass under surge was approximately 0.02 0.07 times the hull mass []. In this paper, the attached

water quality coefficient is set to 0.05 . Therefore, in the collision between the ship and the ice row, the ship's mass is:

$$
M_{\text {ship }}=m_{\text {ship }}+m_{x x}=(1+0.05) m_{\text {ship }}
$$

\section{EFFECT OF ICE BANK THICKNESS ON SHIP-ICE COLLISION}

In order to improve the calculation efficiency, we need to strictly control the calculation time and choose the calculation cut-off time. In general, the determination of the structure failure boundary depends on the specific situation and the trial calculation result. In the collision process of the first ice row of the ship, the bow is impacted by the ice row all the time, and the ship only needs to travel along the bow to expand the channel, so the collision mainly occurs in the bow tip area, and the ship's hull and rudder will not collide with the ice row basically. The calculation time of collision between bow and ice platoon in this section is $2 \mathrm{~s}$, which is sufficient to study the damage of bow structure.

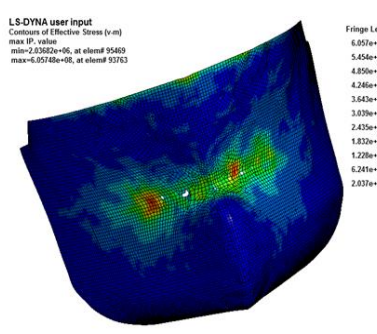

(a) Working condition A

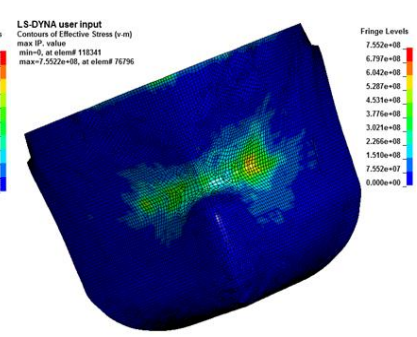

(b) Working condition B

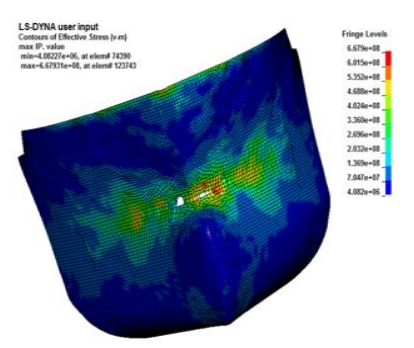

(c) Working condition C

Fig. 1.4 Damage and deformation diagram of bow outer plate under three working conditions

At the moment of collision with $2 \mathrm{~s}$, the contact area between the bow column and the outer plate on both sides and the ice row is damaged the most seriously, and the outer plate extending backward on both sides is damaged gradually as the collision continues: Local areas on both sides of the outer plate also began to suffer large damage at the $1.5 \mathrm{~s}$ moment of collision, which was caused by the extrusion pressure and cutting effect of the outer plate after the ice row was damaged. Moreover, the damage of the outer plate of the ship would cause more serious damage as the collision continued. 


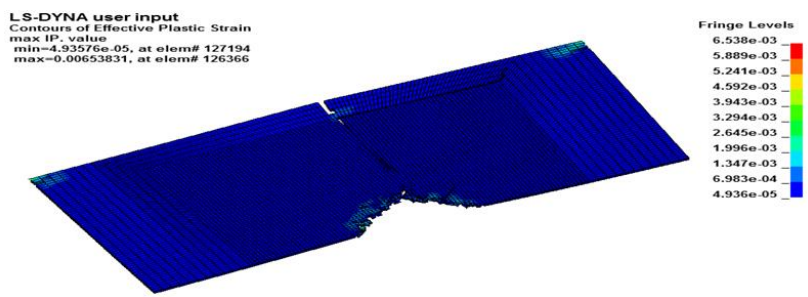

(a) Working condition A d $=0.8 \mathrm{~m}$

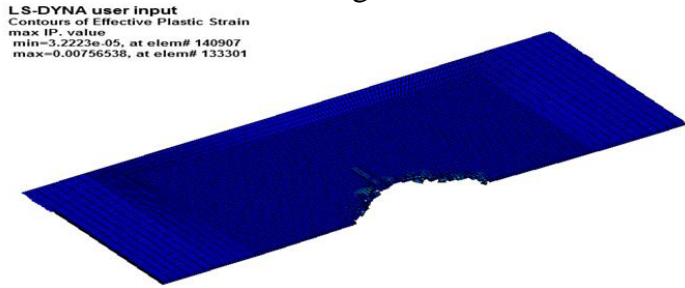

(b) Working condition $\mathrm{B} d=1.0 \mathrm{~m}$

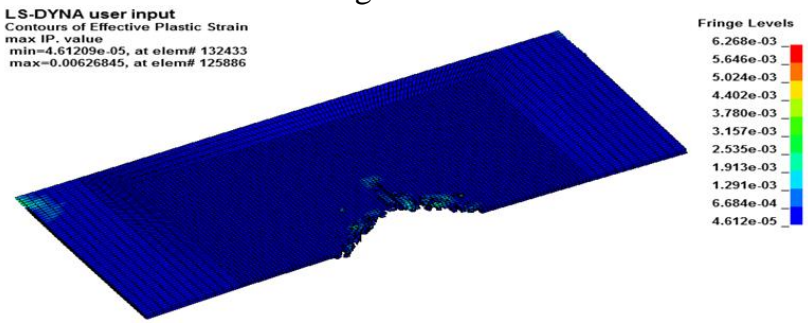

(c) Working condition $\mathrm{C} \mathrm{d}=1.2 \mathrm{~m}$

Fig. 1.5 Deformation map of sea ice damage under three thicknesses

The structural damage maps between the bow and the sea ice collision are summarized. Through comparative analysis, the following conclusions are drawn:

(1) when the bow hits the fixed sea ice at the speed of $5 \mathrm{~m} / \mathrm{s}$, there is a critical point between $0.8 \mathrm{~m}$ and $1.0 \mathrm{~m}$ of sea ice thickness for the ship. Once the thickness of ice exceeds this critical point, the structure of the ship bow will be damaged. And as the sea ice thickness increases, the damage to the bow becomes greater.

(2) by analyzing the structural damage and deformation diagram of sea ice, it can be seen that: There is also a critical value between $0.8 \mathrm{~m}$ and $1.0 \mathrm{~m}$ of sea ice thickness that can change the damage pattern. The ice thickness is greater than the critical value, and the damaged body is only broken and cracked in a small range. On the contrary, the damage can be manifested in two forms: crushing and large area fracture or complete fracture. However, when the sea ice unit in the collision zone does not fail completely, it can be seen that as the sea ice thickness increases, it will become more and more rigid.

\section{EFFECTS OF PHYSICAL PROPERTIES OF ICE ROW ON SHIP-ICE COLLISION}

Numerical simulation analysis was carried out for each working condition in scheme III respectively, and the post-processing software ls-prepost was used for numerical simulation analysis. According to the damage and deformation amount of unfailed unit described by plastic strain, the maximum plastic strain of working condition A was $2.314 \mathrm{E}-1$, the maximum plastic strain of working condition $\mathrm{B}$ was $2.600 \mathrm{E}-1$, and the maximum plastic strain of working condition $\mathrm{C}$ was $2.513 \mathrm{E}-1$. FIG. 1.13 shows the damage stress cloud diagram of the bow outer plate under three working conditions of A, B and C. As can be clearly seen from the figure, under the operating condition $\mathrm{A}$, the ship rammed into the sea ice of $d=0.8 \mathrm{~m}$ at A speed of $5 \mathrm{~m} / \mathrm{s}$. At this time, the material properties of the ice row were the same as that of the operating condition A in scheme I, without any changes. At this time, the ship structure was not damaged, and only A little deformation occurred in some places in contact with the sea ice. In condition $\mathrm{B}$, the shear modulus of the ice row was increased, and damage occurred between the stem column and the outer plate. Working condition $\mathrm{C}$ increased the yield stress. According to the calculated values, the maximum plastic strain was not as large as that of working condition B, and the ship was not damaged. It could be deduced from the subsequent collision force diagram[5].

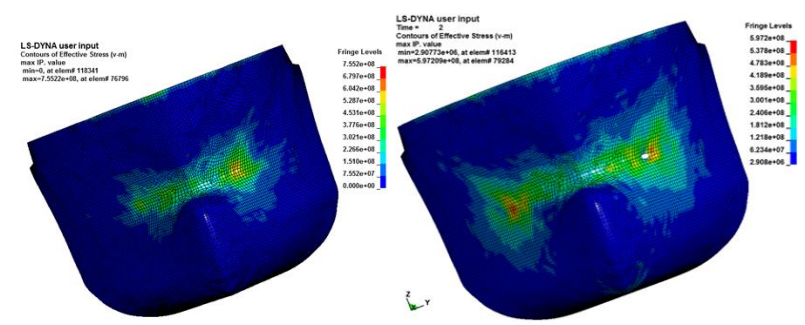

(a) Working condition A (b) Working condition B

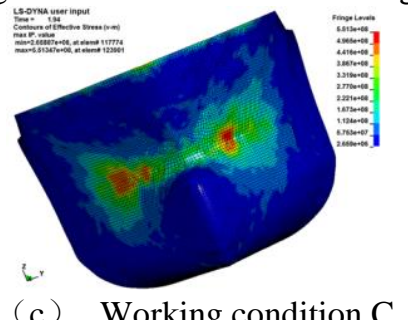

Fig. 1.6 Damage and deformation diagram of bow outer plate under three working conditions

The impact force-time curves of scheme III under three working conditions are shown in FIG. 1.7. In the case of operating condition $\mathrm{A}$, the level of collision force in this case is the lowest than that in the three operating conditions. The stem column of the external plate of the bow does not break, and there is no extreme value in the whole process. In working condition $\mathrm{B}$, the shear modulus was enhanced, and the external plate of bow was cracked. The collision force was unstable and fluctuated greatly at the initial stage of collision, and the collision force reached the maximum value at about $0.7 \mathrm{~s}$ and the extreme value was $2.93 \times 107 \mathrm{~N}$. In the operating condition $\mathrm{C}$, the overall collision force level is between A and B. When it is close to $0.5 \mathrm{~s}$, the initial collision reaches an extreme value of $2.46 \times 107 \mathrm{~N}$. Generally speaking, due to the change of ice material parameters, the loading and unloading times of $\mathrm{B}$ and $\mathrm{C}$ are less than those of $\mathrm{A}$, but the collision force level is higher than that of $\mathrm{A}$.

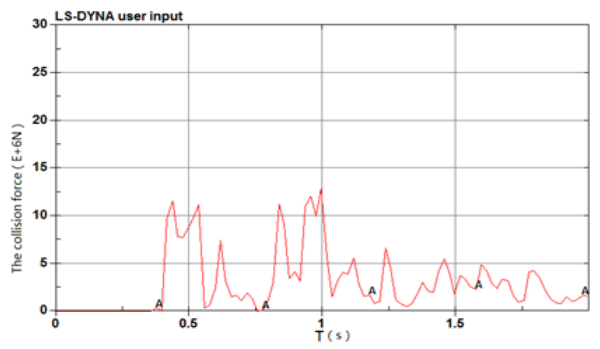

(a) Working condition $\mathrm{A}$ 


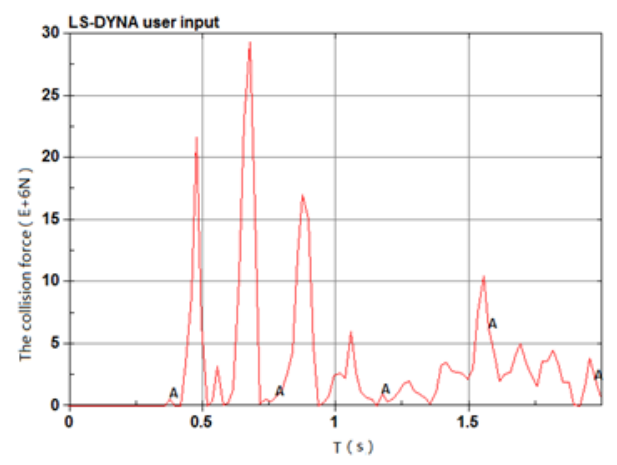

(b) Working condition B

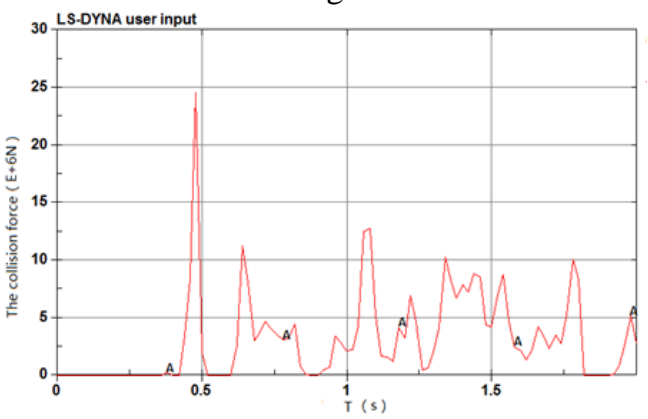

(c) Working condition $\mathrm{C}$

Fig.1.7 Curve of collision force-time

\section{THE SUMMARY OF THIS CHAPTER}

This chapter by ls-dyna software, respectively, from the ice thickness, motion state and physical properties of three aspects, making the three kinds of scheme to simulate the dynamic process of a ice floe collision ship, then for each scheme comparison and analysis, summarized the working condition of the ship, ice floe structural damage deformation, speed change and impact force diagram and research, the main conclusions are as follows:

(1) ships collide with ice platoon. Under non-extreme circumstances, the collision between them is mainly concentrated near the bow ice belt line, and the outer plate and frame structure are the main ice-resistant load members, so the proper strengthening of these two parts is conducive to increasing the collision resistance of ships.

(2) the thicker the ice platoon is, the greater its hardness will be, and the greater the obstruction to navigation ships will be, and the stronger the ice load on ship structure will be, leading to the greater damage degree and range, faster ship speed decline, and larger peak collision force. As for the structure of the ice platoon, as the thickness increases, the form of damage will also change. The cracks will grow from long to short, from existing to non-existing, and the structure will break gradually less.

(3) collision between ship and ice row is buffering, i.e. collision with ice row in free state. Compared with collision with ice row under fixed condition, the slope of ship speed change curve becomes smaller and the level of collision force decreases. The loading and unloading process will almost disappear as the ice row speed gradually approaches the ship speed. From the perspective of the structure of the ice itself, once the collision is not buffered, the ice row will be damaged in a wide range, and the crack growth range will be larger.

(4) only by increasing the shear modulus and yield strength of the ice row, the stress on the outer plate of the bow column increases and even damages may occur. It can be seen from the change curve of collision velocity that the ship's velocity does not change much. In both cases, the number of times of impact unloading decreases slightly but the peak value increases. From the point of view of ice structure itself, the former only produces small cracks accompanied by surface fracture, while the latter produces relatively slight surface fracture and the cracks are not as large as before[6-7].

\section{REFERENCES}

[1] D.M. Masterson, R.M.W. Frederking. Local contact pressures in ship/ice and structure/ice interactions[J]. Cold Regions Science and Technology, 1993(21): 169-185.

[2] Motora S , Fujino M , Sugiura M , et al. EQUIVALENT ADDED MASS OF SHIPS IN COLLISIONS[J]. Journal of Colloid \& Interface Science, 1971, 207(2):309-316.

[3] Bass DW, Sen D. Added mass and damping coefficient for certain 'realistic' iceberg models[J]. ColdReg Sci Technol 1986; 12(2): 163-74..

[4] Liu Zhenhui. Analytical and numerical analysis of iceberg collisions with ship structures[D]. Norwegian University of Science and Technology, Norway, 2012..

[5] Liu Zhenhui, Amdahl J, Loset S. Integrated numerical analysis of an iceberg collision with a foreship structure[J]. Marine Structures, 2010, 22(2): 1-19..

[6] Lee S G, Lee J S. Structural safety assessment in memberane-type CCS in LNGC under iceberg collisions[C]// ICSOT 2009: Ice Class Vessels. Busan, Korea.

[7] Wang Bo, Yu Hanchang. Ship and ice collison modeling and strength evaluation of LNG ship structure[C]// OMAE2008. Shanghai, China, 2008 . 